Bruhns, H.T.; Marinho, A. Ritos e rituais nas viagens à natureza. Revista Brasileira de

Ecoturismo, São Paulo, v.5, n.1, jan/abr-2012, pp.87-102.

\title{
Ritos e rituais nas viagens à natureza
}

Rites and rituals in travels to nature

\section{Heloisa Turini Bruhns, Alcyane Marinho}

\section{RESUMO}

Este ensaio, que se fundamenta em resultados de pesquisas qualitativas que seguiram a linha da observação participante, pretende explorar alguns ritos e rituais presentes nas buscas pela natureza e para tal desenvolve reflexões nas quais são apresentados alguns elementos que contribuem para essas ritualizações como a própria viagem e, nela, momentos nos quais ocorrem "cerimônias" consideradas relevantes, como o ritual do silêncio e o ritual do pôr do sol. Essas ritualizações nos transportam para momentos de excepcionalidade transformando situações corriqueiras em algo extraordinário e sentidos diferenciados são atribuídos às ações. Neste contexto, a aventura sendo entendida como uma possibilidade de experiência nova, algo além do ordinário, traduz sua dinamicidade e multiplicidade de possíveis experimentações, bem como revela uma perspectiva estética, permitindo a vivência individual e coletiva de inúmeras sensações e emoções, as quais, neste ensaio, são discutidas a partir dos ritos e dos rituais na natureza. Espera-se com as discussões empreendidas contribuir com novos desafios que se apresentam sobre os assuntos expostos, fortalecendo o repensar sobre importantes aspectos da vida atual, especialmente atrelados à natureza.

PALAVRAS-CHAVE: Cultura; Ritos; Natureza; Aventura.

\section{ABSTRACT}

This essay, which is based on results of qualitative research that followed the line of observation, explores some rites and rituals in travels to nature. It leads to a reflection on the elements that contribute for these ritualizations as the trip itself through which special "ceremonies" happen like the silence ritual as well as the sunset ritual. These ritualizations might inform how people introduce different meanings in their lives transforming habitual situations into exceptional events. In this context, the adventure is viewed as an opportunity to new experience, something beyond the ordinary, translates its dynamism and its multiplicity of possible experiments, and reveals an aesthetic perspective, allowing the individual and collective experience of many sensations and emotions, which, this paper, are discussed from the rites and rituals in nature. It is expected with these discussions to contribute with new challenges that present themselves on the subjects exposed, strengthening rethink about important aspects of actual life, especially linked to nature.

KEYWORDS: Culture; Rites; Nature; Adventure. 


\section{Introdução}

Vive-se um momento na história humana em que o desenvolvimento tecnológico e as condições de vida no ambiente urbano parecem afastar as pessoas do convívio com o ambiente natural, mediante a proliferação de shoppings centers, de condomínios fechados, e outros; no entanto, contraditoriamente, é crescente o número de pessoas que busca estar, de alguma forma, em contato com os elementos naturais, tais como rios, trilhas, cachoeiras, montanhas, etc. Embora a ideia de vivenciar aventuras em contato com a natureza não seja nova, há motivações, significados e consequências claramente peculiares à contemporaneidade (MARINHO, 2008).

Discussões que contextualizam a busca por práticas de aventura, esportivas, de lazer e turísticas junto à natureza podem ser encontradas na literatura nacional (COSTA; MARINHO; PASSOS, 2007; FIGUEIRA; GOELLNER, 2009; MARINHO, 2008, 2006; PEREIRA; ARMBRUST, 2010; PIMENTEL; SAITO, 2010; TEIXEIRA; MARINHO, 2010) e na literatura internacional (BERNARDO; MATOS, 2003; BETRÁN; BETRÁN, 1995; CARNICELLI FILHO; SCHWARTZ; TAHARA, 2010; HUMBERSTONE, 2009; MARINHO; NASCIMENTO; HUMBERSTONE, 2011; PIMENTEL, 2008).

Inúmeros fatores indicam o crescimento expressivo da visitação em áreas naturais no Brasil e no mundo e, de acordo com uma pesquisa realizada pelo Ministério do Meio Ambiente, as atividades de aventura na natureza se enquadram entre os segmentos mais promissores do mercado de turismo, com um crescimento mundial estimado entre $10 \%$ e $30 \%$ ao ano (BRASIL, 2006).

Diversas iniciativas têm se mostrado significativas, contribuindo para situar o tema em questão, tais como: crescente produção científica; maior visibilidade e reconhecimento em eventos científicos em várias áreas do conhecimento, nos âmbitos regional, nacional e internacional; oferecimento de disciplinas optativas e obrigatórias, cursos de extensão, graduação e pós-graduação em diferentes áreas do conhecimento, em distintas faculdades e universidades do Brasil; desenvolvimento de vários trabalhos com diferentes populações, entre outras iniciativas.

Partindo desta perspectiva e acreditando que a aventura na natureza é capaz de oportunizar o estabelecimento de novas relações entre os seres humanos por meio da criação de laços de amizade e da vivência de sensações e emoções, o tema deste ensaio apresenta-se como uma oportunidade relevante para que a vida social contemporânea seja refletida na perspectiva de um novo olhar, reiterando a importância teórica de estudos deste teor.

As ideias aqui apresentadas partem do princípio de que os espaços rituais governam boa parte da vida e muitos podem assim ser considerados como praças, montanhas, praias, etc., nos quais atividades coletivas são desenvolvidas com propósitos e objetivos comuns.

O acontecimento é sancionado com uma "cerimônia" considerada relevante para o grupo ou sociedade em que está inserido. A sucessão de fatos e de cerimoniais 
tende a deslocar o acontecimento ou transformá-lo de algo corriqueiro em algo especial ou extraordinário, atribuindo uma espécie de permanência no tempo, a qual é determinada pela presença particular de um "lugar delegado" ou "tempo delegado".

Uma forma de dramatização é necessária e por ela tomamos consciência das coisas ou fatos e passamos a vế-las como tendo um sentido. O ritual possui como traço distinto a dramatização, isto é, a condensação de algum aspecto, elemento ou relação, posicionando-o em destaque, com um foco especial. Esse cerimonial constituise em um estado passageiro e acontece quando a sociedade sai de si própria entrando em uma ambiguidade, em um estado diferente daquele que normalmente ocorre ou poderia ocorrer.

Há uma sugestão de que o momento extraordinário possa continuar não mais como rito com "tempo delegado" ou "lugar delegado", mas como algo extraordinário que possa se prolongar (DA MATTA, 1983), abrindo, portanto, possibilidades para novas ideias, novos comportamentos, novas formas de se relacionar com a vida.

As viagens à natureza relacionam-se a determinados ritos e rituais. Talvez o mais evidente e marcante seja o rito de passagem envolvido na própria viagem, no qual identidades são construídas e nutridas por subjetividades. A busca pelo ambiente natural implica em um deslocamento, incorporando aspectos relacionados ao trânsito, à viagem, ao movimento, à errância.

A intensidade dos deslocamentos contemporâneos e fluxos de pessoas, mercadorias, imagens, informações, muitas vezes ultrapassando fronteiras, produz um contato diferenciado e intensificado, dissolvendo barreiras. Temos pessoas com vidas mais móveis sentindo-se à vontade com identidades mais fluídas, e essa mobilidade é considerada uma das chaves metodológicas para a compreensão da atualidade, reunindo alguns elementos como incerteza, desterritorialização, dentre outros.

Bauman (1999, p.8) situa o movimento como um valor bastante cobiçado em nossa contemporaneidade, sendo, porém, a liberdade de movimento, uma mercadoria escassa e distribuída de forma desigual, tornando-se um elemento estratificador (ser situado em um mundo globalizado é sinal de privação e degradação social). O movimento revela-se mesmo quando estamos fisicamente imóveis, sendo irrealista a opção da imobilidade no atual contexto de permanente mudança ("não se pode ficar parado em areia movediça"). A ideia de "estado de repouso" não faz muito sentido em um mundo com pontos de referência sobre rodas, os quais costumam sumir de vista antes da possibilidade de leitura das instruções sobre o trajeto.

A distância parece não importar muito, às vezes existindo para ser anulada, deixando o espaço de ser um obstáculo, bastando frações de segundos para conquistálo. Nesse sentido podemos pensar a busca da natureza e de seus lugares longínquos como uma possibilidade atual para vivências distintas. Também como um movimento global, pois não se vinculam a um ou outro país, desvendando a desterritorialização do espaço. Se o entendimento de um mundo desterritorializado requer um ponto de vista desterritorializado (ORTIZ s/d, p.16), podemos pensar essas práticas na nature- 
za inseridas na ordem interna da sociedade global, expondo sua face mundializada ${ }^{1}$. Discutir sobre uma cultura mundializada representa nos colocarmos no âmago desse processo abrangente, situando-a no nosso cotidiano, nos nossos hábitos. Para Ortiz (s/d), "a mundialização da cultura não é falsa consciência, uma ideologia imposta de forma exógena", mas corresponde a um processo real, transformador do sentido das sociedades contemporâneas. As manifestações desta mundialidade encerram verdades, as quais se expressam na vida cotidiana.

Desta forma, partindo destas considerações, este artigo pretende explorar como a busca contemporânea pela natureza está imbuída de ritos, trazendo elementos que possam contribuir para o debate presente em aspectos envolvidos na temática da relação homem/natureza. Para tal, além do rito de passagem, foram eleitos o rito do silêncio e o do pôr do sol, por serem frequentes durante a execução de trilhas na natureza.

Esse ensaio parte dos resultados obtidos em pesquisas realizadas com subsídios do CNPq para sua realização ${ }^{2}$. Receberam um tratamento qualitativo na organização dos dados e seguiram a linha da observação participante, na qual houve inserção no grupo pesquisado, realização de viagens, participação de reuniões, seguindo um roteiro de contatos indicados pelos sujeitos da pesquisa, com agentes de viagens, grupos organizados e coordenadores das atividades. Buscou-se uma adaptação aos grupos de acordo com a execução do calendário de viagens, disponibilidades para entrevistas, convites recebidos etc.

Algumas fases foram estabelecidas para o percurso das pesquisas. Primeiro, a montagem institucional com a explicitação do objeto e a definição do quadro teórico (conceitos, objetivos e outros). A segunda fase constituiu-se em uma seleção gradativa dos sujeitos e grupos selecionados, havendo um perfil a ser buscado relacionado aos adeptos da modalidade eleita. A terceira fase centrou-se na identificação dos grupos e suas características, buscando a compreensão de sua lógica interna, contradições e conflitos, bem como a detecção dos problemas intrínsecos.

O tema foi explorado a partir dos elementos surgidos nos grupos pesquisados por meio das observações e entrevistas, em um diálogo estabelecido com a bibliografia selecionada. Foi considerada a realidade social dos envolvidos, a qual possui um significado específico e uma estrutura de relevância para os mesmos, sendo suas falas apreciadas a partir do lugar social que ocupam nessa realidade. As relações de pensamento construídas na pesquisa buscaram compreender essa realidade social, e basearam-se nas relações de pensamento construídas pelo senso comum dos sujeitos que vivem sua vida cotidiana no contexto de sua realidade sociocultural. Então, o conhecimento construído, aqui, representou o resultado de um "saber negociado", em que há uma confrontação constante entre pesquisador e pesquisado. Nesse quadro como coloca Cicourel (1975, p.110), o pesquisador "precisa distinguir as racionalidades científicas que usa para ordenar sua teoria e seus resultados, das racionalidades do senso comum que atribui aos atores estudados", uma vez que esses dois conjuntos de constructos (científico e senso comum) são considerados pelo pesquisador. 


\section{O rito de passagem na busca pela natureza}

Para o viajante, a viagem não é uma continuação da sua vida, mas um momento distinto, marcado pelo antes e depois. Representa um estágio "especial" de sua existência, na qual se permite sair da condição doméstica para entrar na condição estranha. Saindo do seu cotidiano, de sua cultura, de seus referenciais, entra em outro tipo de existência. O tempo nesse espaço não é o tempo do seu cotidiano, mas o "tempo da viagem", oscilando entre o mundo vivido e o mundo representado. Na condição de viajante pode incorporar como parte de sua existência o almejado, o permitido e o possível (LEITE, 1996). Neste "estado de viagem" o tempo da narrativa se desloca e se define.

Pensando nos ritos de passagem, esse estado entre a partida e a chegada, seria a fase liminar ou de "transição", ou seja, um período intermediário em que os sujeitos são a margem, a indefinição, a "linearidade" e no qual há uma tentativa de vencer o desconhecido. Leite (1996, p.86) mostra como as viagens são marcadas por ritos de separação, margem e agregação. Esses ritos se repetem a cada saída e chegada do viajante em ambientes novos, em lugares desconhecidos e essa seqüência, não o relógio, marca o tempo. No retorno, marca final do rito de passagem, o sujeito está transformado pela experiência vivida. Alguns saem como aventureiros e retornam como "heróis" dessas pequenas façanhas na natureza, enquanto outros partem como curiosos e retornam como "viajados" ou "experientes" (BRUHNS, 2009).

Bryson (1999) escrevendo sobre sua experiência na Trilha dos Apalaches, um longo percurso para caminhada (aproximadamente $3000 \mathrm{~km}$ ) nos EUA, auxilia nessa reflexão sobre o tempo. O autor descreve como a vida reveste-se de uma simplicidade límpida nessa experiência, deixando o tempo de ter qualquer sentido. Quando está escuro você vai para a cama e, quando fica claro de novo, você levanta. Não há obrigatoriedade de encontros, reuniões, deveres e nenhuma ambição especial, apenas necessidades menores e bem menos complicadas; você encontra-se no meio de um tédio tranquilo, sereno, alheio a toda exasperação, afastado dos centros de discórdia; a única exigência é a disposição para caminhar, apesar das dificuldades. O apressarse não faz sentido, porque você não está indo a parte alguma. Por mais que caminhe está no mesmo lugar: na mata, local onde estava ontem e onde estará amanhã.

As noções de distância alteram-se durante o percurso de uma trilha na mata. Dois quilômetros são uma distancia longa, três quilômetros tornam-se literalmente notáveis, quinze colossais, e oitenta quase inconcebíveis. Caminhando, você se dá conta de que o mundo é enorme, de um modo que só você e seus companheiros andariIhos sabem. A escala planetária torna-se um pequeno segredo seu.

Nessas aventuras a espacialidade privilegiada é o local e a temporalidade privilegiada o imediato. A experiência implica em certo desconforto, pois envolve situações inusitadas investindo no transitório, no efêmero (BRUHNS, 2009).

As pequenas aventuras vividas nas caminhadas e trilhas representam uma totalidade de vida no sentido de um modelo reduzido, contraindo experiências e poten- 
cialidades. Sendo a aventura o terreno do possível, as facetas dos sujeitos podem se exprimir em um mundo plural e policentrado. A aventura garante uma mobilidade naquilo que está petrificado, pois ela incorpora um aspecto de removedor, permitindo o olhar para o exterior (MAFFESOLI, 2001).

Referindo-se ao aventureiro, Simmel (1988) argumenta sobre este constituir o exemplo mais forte do homem a-histórico, da criatura do presente; e, se por um lado, não se acha determinado por nenhum passado, por outro o futuro não existe para ele.

A questão da aventura não está em ganhar ou perder, portanto, não consiste nos conteúdos ganhos ou perdidos, gozados ou sofridos, pois esses elementos estão presentes em outros campos da vida. Trata-se somente de um fragmento da existência, ao lado de outros, o qual possui a força misteriosa de fazer-nos sentir por um momento, a vida inteira, como se não tivesse outro objeto senão sua realização.

A aventura implica naquilo que Maffesoli (2001) denomina por "enraizamento dinâmico", ou seja, uma dialética permanente entre a necessidade de segurança e o desejo por aventura. Dessa forma, introduz a agitação no estável ou a inquietude nas certezas, desestabilizando alguns parâmetros da modernidade como a domesticação das massas, do assentamento no trabalho e no destino à residência.

De acordo com Marinho (2006), a aventura está atrelada à ideia de busca pelo desconhecido, desejo de exploração, retorno ao nomadismo e a uma possibilidade de ficção, ressignificando modelos e, de certa forma, despertando novos comportamentos dos sujeitos envolvidos. $O$ nomadismo e a ficção permitem lançar a ponte entre o ordinário e o extraordinário da vida, não se satisfazendo com vivências estáveis, funcionalistas e meramente racionais, mas usando a pluralidade dos sujeitos, por intermédio da fantasia, da imaginação, do imaterial e do lúdico. Ratificando, com isso, que as viagens à natureza são alternativas fecundas para a compreensão das redes que se formam, na atualidade, entre as pessoas e o ambiente natural, baseada em laços mais descompromissados e efêmeros, porém, verdadeiros e intensos.

$\mathrm{Na}$ "brincadeira de aventura na mata", onde a vida torna-se momentaneamente livre atuação de formas, despojada de propósitos ulteriores, o ato heróico igualmente surge como simulacro, uma vez presenciando-se nessas atividades, certa dose de "coragem", um "provar algo a si mesmo", almejando metas extraordinárias. Na figura do herói como simulacro está presente a possibilidade de uma transgressão ou rejeição da ordem, a qual gira em torno do mundano, do ordinário. Nesse simulacro, ausentam-se imagens da dedicação a alguma causa impessoal, de uma autorrepresentação racionalizante e justificadora. Como, por exemplo, a exaltação das virtudes do sacrifício, distinção, disciplina, presentes em questões políticas institucionais, ou na dedicação a alguma causa envolvendo abnegação e dedicação exclusiva como nas opções de vida por causas humanitárias condizentes aos grandes heróis da história. Surge um heroísmo nãoestóico, no qual uma série de aventuras ou a qualidade de uma aventura é compartilhada. O aventureiro tem o gesto do "conquistador", construindo um sistema "a partir da ausência de sistema em sua vida" (SIMMEL, 1998). 
Presencia-se nessa busca contemporânea pela natureza uma ética da sociabilidade contrapondo-se à ética do herói, menos elevada, mais aberta a uma exploração igualitária da ludicidade e do prazer com o outro, à imersão e à perda do eu, mais que a uma preservação e elevação do eu. Essa atividade pode representar, neste sentido, um fator de distinção, em um contexto investindo contra a vida heróica estóica, em uma forma lúdica de associação, em que se brinca de ser herói, em uma simulação do perigo e do risco (FEATHERSTONE, 1997, p.97).

No retorno, o sujeito está marcado pela experiência vivida, mas é justamente na transição, na situação liminar, que ocorrerão experiências da exploração, da conquista, da aventura, da coragem, às vezes, do sacrifício, da privação, do desconforto. Nessa fase liminar, identidades irão aflorar como, por exemplo, a identidade de aventureiro, a qual não responde às certezas identitárias ou seguranças institucionais. Essa identidade cultural não é rígida, nem imutável. O eu contemporâneo é apresentado como uma entidade que se apresenta de formas diferentes em cenários diversos, em um contraponto à ideia de identidades sólidas, coerentes, integradas (BRUHNS, 2006, p.98).

A ideia é a de identidades em movimento, frágeis, múltiplas e contraditórias, constituídas no fundamento sólido da existência individual e social. São resultados transitórios e fugazes de processos de identificação. Além de plurais, são dominadas pela obsessão da diferença e pela hierarquia das distinções. Desta forma, devemos ter como preocupação quem pergunta pela identidade, em que condições, contra quem, com que intenções e com quais resultados (SANTOS, 2003). Não há um sujeito ou subjetividade fora da história e da linguagem, da cultura ou das relações de poder. As identidades, ou a identificação ${ }^{3}$ são produzidas por meio da diferença, a qual ocorre tanto por meio de sistemas simbólicos de representação quanto por meio de formas de exclusão social.

O grupo social onde a identidade se manifesta é formado por uma comunhão sensível ou afetiva por "indivíduos que acreditam" - comparam, fazem escolhas, reconsideram escolhas, tentam reconciliar demandas contraditórias e, frequentemente incompatíveis (BAUMAN, 2005).

A identidade de aventureiro constitui-se num dos tipos a ser experimentado - é um campo de experiência, de afeto, de marcas de sonho, de abertura por meio de conexões e fugas, de criação e sentido, de agenciamento coletivo, de produção de si. Através de fluxos de imagens, de informação, de conhecimento e serviços, consumimos subjetividades e absorvemos maneiras de ser, sentidos de vida. A identidade de aventureiro será reforçada, ou não, por intermédio da subjetividade - no que acreditamos, no que valorizamos, e no que privilegiamos.

A subjetividade sugere a compreensão que temos do nosso eu e a experiência que temos de nós mesmos. Nela adotamos uma identidade. Por meio da subjetividade é possível explorar sentimentos e valores envolvidos nesse processo, bem como o investimento pessoal em posições específicas de identidade. 
A identidade de aventureiro é cultural e poderíamos pensar qual seria, por exemplo, a identidade cultural dos praticantes de caminhada da Chapada Diamantina (BA). Certamente não se refere à caminhada ou às aventuras, portanto, ao que o grupo faz, mas, sim como o grupo faz, por meio da utilização de determinada roupa, equipamentos, valendo-se de determinada linguagem, postura, da composição de seus membros, etc. Refere-se mais a uma questão de estilo e forma.

\section{0 rito do silêncio}

Porque tornar o silêncio um rito e prepararmos um momento especial para ele? Essa questão exige uma exploração sobre o significado e as implicações sociais do silêncio envolvidos em nossa cultura.

Ao tomarmos consciência do silêncio ou quando o encontramos em nossa vida, estabelecemos uma ligação com a dimensão sem forma e constante dentro de nós mesmos - aquela além do pensamento e do ego. Pode ser o silêncio que envolve o mundo da natureza, a tranqüilidade do nosso quarto nas primeiras horas da manhã ou o intervalo entre os sons. Ter consciência do silêncio significa estar em silêncio experimentando um contato muito intenso com nós mesmos. No silêncio está implícita uma dimensão espacial.

O aspecto do silêncio merece ser explorado, pois é sempre requisitado nessas viagens à natureza, como uma espécie de exercício dos sentidos ou um apelo para as pessoas centrarem-se no espaço. O objetivo é que as pessoas fiquem mais atentas a si mesmas em uma conexão com o ambiente. As sensibilidades em relação aos sons externos provenientes do meio natural (muitas vezes não familiares aos sujeitos urbanos) são potencializadas e despertam curiosidade. Torna-se quase um teste de acuidade auditiva.

No nosso contexto social, um homem em silêncio é um homem sem sentido o qual não suporta a ausência das palavras e daí perguntas surgem: "Porque você está quieto? O que está pensando?" Por não ser suportado, os sujeitos fazem do silêncio algo fugaz e efêmero.

As pessoas anseiam por fazer o silêncio falar, exercendo controle e disciplina, ou ao contrário; supondo poder calar o sujeito, emitem sinais sonoros (dizíveis, visíveis) continuamente, produzindo signos de controle pelo que "aparece". Abrem mão do risco da significação, da sua ameaça e se preenchem falando. O espaço é atulhado com sons e a ideia de silêncio é concebida como falta, como vazio. Quando negamos nossa relação fundamental com o silêncio apagamos medições que nos são básicas (ORLANDI, 2002).

Quando não falamos, não estamos somente mudos, estamos em silêncio, estando presentes o pensamento, a introspecção, a contemplação, etc. Temos múltiplos silêncios, tais como o das emoções, o do místico, o da contemplação, o da introspecção, o da revolta, o da disciplina, o do exercício do poder, o da derrota da vontade, 
etc. Pensar o silêncio é pensar tanto a solidão do sujeito como a história solitária do sujeito face aos sentidos.

A concepção freqüente do silêncio é a mítica, pois é um tema cuja história está atrelada ao sagrado, às religiões. Considerado como "um apoio à adoração" ou como "método que prepara a alma para experiências pessoais", foi praticado por pequenos e grandes grupos em muitos períodos da história ao redor do planeta (ORLANDI, 2002). Além de sua qualidade física, o silêncio é história (silêncio humano), sentido, matéria significante, bem como é produzido em determinadas condições e aqui se ressalta sua materialidade histórica. O silêncio atualmente, para alguns, representa cada vez mais um luxo.

Tomando como exemplo o que Schaffer (1977) denomina de "paisagem sonora", podemos extrair de seu trabalho alguns elementos enriquecedores para esta discussão. $O$ autor destaca algumas peculiaridades condizentes ao cenário rural e ao urbano. No urbano, a transformação da "paisagem sonora" passa da "alta fidelidade" para a "baixa fidelidade" e informações acústicas comuns ou conflitantes encobrirão os sons desejados ou necessários. Um som deve ser muito forte ou insistente para atrair nossa atenção. Os sons ocorrem concomitantemente (buzinas, motores de carro, sirenes), desperdiçando energia acústica e provocando a destruição dos nervos e tímpanos. Seu estudo mostra ser preciso reduzir o volume sonoro total, para podermos novamente ouvir com clareza sons diminutos ou portadores de mensagens.

No meio urbano, os sons são próximos e no rural, distantes, pois a "paisagem sonora" no primeiro caso tem presença, sendo que o segundo, além dessa, possui horizonte acústico. O ouvido capta qualquer sinal de invasão. Algumas vezes, o ouvir à distância torna-se vital para a sobrevivência de uma comunidade. Schaffer (1977) explora esse tema em uma pesquisa realizada na aldeia de pescadores de Lesconil (Grã Bretanha), em que o ciclo diário dos ventos que sopram do mar envolve o povoado em sons vindos de todos os pontos do horizonte, alguns de uma distância de 12 quilômetros. Ouvem-se os sinos de cidadezinhas longínquas, os sons do campo, os sinais das bóias situadas em diferentes pontos do mar, cada um a seu tempo. Qualquer modificação no sistema habitual indica uma mudança do tempo, que os ouvidos treinados do pescador ou de sua mulher captam imediatamente.

Por intermédio de um programa de computador, compilando um catálogo de descrições feitas por escritores de todas as épocas e nacionalidades, Schaffer (1977) realizou comparações estatísticas sobre o aparecimento e desaparecimento dos diferentes sons que figuram nos índices. Na literatura europeia do século XIX, $43 \%$ dos sons mencionados são naturais. Caem para $20 \%$ no século $X X$, diferindo entre América do Norte e Europa, onde no primeiro caso, não foi constatado um declínio tão acentuado, devido provavelmente, segundo Schaffer (1977), ao maior contato dos americanos do norte, com o ambiente natural, diferentemente dos europeus, para os quais esse contato foi bastante diminuído.

Quanto ao silêncio e à quietude, houve uma redução significativa no número de 
referências. Nos arquivos pesquisados, 19\% das descrições relativas às décadas de 1810-1830 mencionam a quietude e o silêncio; entre 1870-1890 caem para $14 \%$ e entre 1940-1960 para 9\% (SCHAFFER, 1977).

$\mathrm{Na}$ descrição para o silêncio, comumente se observa o emprego de alguns termos como opressivo, insensível, terrível, deprimente, dentre outros. A quietude e o silêncio evocados por essas palavras quase nunca são positivos, sendo que raramente se considera o silêncio de um passeio contemplativo pelos campos, nem o que se observa quando se ouve música; não é o silêncio da fascinação ou da meditação, nem mesmo o do sono. Talvez nossa atitude em relação a elas esteja necessitando de uma revisão.

\section{O rito do pôr-do-sol}

É prática comum em viagens à natureza o grupo se reunir no final da tarde com o objetivo de assistir o pôr-do-sol. Em 2003, durante o acompanhamento de um grupo de ecoturismo em Carrancas (MG), esse fato ocorreu durante três dias consecutivos. No primeiro e no terceiro dias, as pessoas seguiram de ônibus até determinado ponto, e de lá caminharam até um cume em que todos sentaram para aguardar o momento do crepúsculo. No segundo dia isso ocorreu durante a trilha, coincidindo o momento do pôr-do-sol com um local propício, conhecido do guia, para visualizar o fenômeno.

É interessante citar alguns rituais do pôr-do-sol em lugares já consagrados para essa finalidade, envolvendo as trilhas na natureza e muitos participantes, tal como - Morro do Pai Inácio na Chapada Diamantina (BA), o qual se tornou um marco de identificação do local; a duna do pôr-do-sol em Jericoacoara - Fortaleza, na qual não só turistas sobem para assistir ao espetáculo, mas também moradores locais, os quais, normalmente, organizam uma roda de capoeira. Garotos residentes permanecem até o escurecer escorregando pelas dunas e fazendo acrobacias com o corpo como, por exemplo, a execução de saltos mortais e piruetas. Outro local onde o ritual é bastante intenso é no Deserto do Atacama - Chile, no Vale da Lua, na Grande Duna, onde centenas de turistas, de várias partes do planeta, permanecem para assistir a esse fenômeno.

Segundo Schelle (2001, p.182), sentimos uma influência marcante das tardes no nosso íntimo porque à tarde a atividade da imaginação é mais estimulada. É quando as emoções e as paixões violentas se acalmam em uma organização mais internalizada, sendo o momento do dia mais propício para reflexões. Esse momento, diz o autor "faz sentir à alma sua necessidade de amor e de amizade, e abre o coração para a confidência, mas o expõe também, segundo a própria natureza das coisas, aos sentimentos de medo, de temor de receio e de terror".

Nery (2002) desenvolve interessantes considerações a esse respeito partindo das diferenças entre o alvorecer e o entardecer. No primeiro ocorre um anúncio antecipado, mas resumido dos vários momentos que se sucederão ao longo do dia, sem um formato acabado desses momentos, sem prescrição acabada das tonalidades. Ao 
contrário, o pôr-do-sol apresenta-se como uma representação com começo, meio e fim, agrupando as tonalidades de cores apresentadas pelo céu durante o dia, como brilho do sol ao meio dia, meia claridade e, finalmente, escurecimento. Assim, o instante do crepúsculo concentra, de forma breve, intensa e curta, como em um modelo reduzido, as várias colorações do dia, permitindo sua captação pela observação humana como se fosse numa cápsula de imagem. Manifesta-se um prazer na recordação de momentos já vivenciados, o qual "decorre justamente do fato de se poder fazêlo de modo a filtrar os percalços por ventura transcorridos por ocasião da vida real da experiência em seu modo original, uma vez que, seletivamente, se arranja na memória algo que se espera reencontrar como imagem significativa" (NERY, 2002, p.71).

A recordação da vida (como um conto narrado), embora seja diferente da própria vida (experiência vivida), é uma característica humana e não se efetua de forma linear, devido à filtração dos percalços. A imagem do pôr-do-sol conecta na inteligência humana uma metáfora da vida, ainda que em forma de uma homologia (pois narrativa e experiência são diferentes), concentrando em um único foco de olhar a imagem condensada da passagem (contendo começo, meio e fim) de um dia que está findando.

Nessas viagens à natureza, as recordações do dia tornam-se mais prazerosas, pela intensidade acentuada, tanto das relações, como das emoções vividas pelas descobertas e estímulos dos sentidos. Daí os estados de êxtase provenientes dessa experiência possam ser mais bem compreendidos.

No tempo vivido, curto e intenso dessas atividades na natureza, o pôr-do-sol representa uma situação a qual faz coincidir uma expectativa criada sobre a vida e sua efetiva realização, ou seja, ocorre uma realização do que antecipadamente construímos na imaginação, provocando um sentimento de completude.

O panorama de um pôr-do-sol é um fenômeno emocionalmente competente na medida em que desencadeia emoções. Porém, o estado do corpo como resultado dessa contemplação constitui o cerne do sentimento.

Assistindo a um pôr-do-sol, subitamente você se esquece de desejos, ansiedades, pensamentos indesejáveis. Você elimina momentaneamente a ânsia por prazer ou por aquilo convencionalmente denominado por "felicidade". O pôr-do-sol pode atingir o sujeito de uma forma súbita e intensa, fazendo-o esquecer do passado e do futuro; somente o presente existe. Ele está ligado ao momento; não há observador e um observado; não está separado do que está assistindo. Nessa fusão surge uma sensação de bem estar, de tranquilidade (BRUHNS, 2009).

A partir da experiência do corpo relacionada a estados aprazíveis considerados "bons" e "positivos" ou o contrário, estados considerados "ruins" ou "negativos" no panorama geral da vida, identificamos pensamentos como felizes ou tristes. Essa identificação seria prejudicada na ausência dessa experiência.

A aprendizagem e a recordação dos fenômenos e situações emocionalmente 
efetivas, igualmente são apoiadas pela presença dos sentimentos. A memória de determinadas situações faz que, conscientemente ou não, acontecimentos associados com sentimentos negativos sejam evitados e situações que possam causar sentimentos positivos sejam buscadas. O conteúdo do sentimento relacionado a uma experiência agradável ou não, intensa ou não, relaciona-se com os componentes mentais, com os ingredientes que constituem esse mesmo sentimento.

Tomando emprestado o exemplo de Damásio (2004), imagine-se em uma praia, deitado na areia, com o sol do final da tarde aquecendo sua pele, uma brisa acariciando seu rosto e provocando um ligeiro movimento nos arbustos ao redor e o barulho do mar envolvendo a cena. Provavelmente você já tenha experimentado essa situação e tenha sentido um bem-estar e a questão refere-se em que consiste esse bemestar. Talvez ele tenha vindo da temperatura confortável ou da respiração tranqüila, liberta de qualquer resistência no peito ou na garganta. Os músculos estavam relaxados, não exercendo tensões nas articulações. Era possível sentir o organismo como um todo, funcionando sem problema. Você poderia se movimentar, mas preferiu permanecer quieto, paradoxalmente situado entre a inclinação de agir e o saborear da quietude. Algumas dimensões no corpo eram facilmente identificáveis, mas talvez fosse difícil localizar em um ponto exato do corpo a sensação de bem estar daquele momento.

O sentimento do momento estava gerando duas conseqüências. A primeira foram os pensamentos cujos temas eram consoantes com a emoção e o sentimento da experiência. A segunda um modo de pensamento, um processo mental aumentando a velocidade da geração das imagens mentais, tornando-as mais abundantes. Aquilo que os sujeitos consideram como "corpo" e "espírito" juntavam-se perfeitamente em harmonia. Todos os conflitos, motivos de preocupação antes daquele momento, dissiparam-se e constituíam-se em memórias distantes.

\section{Considerações finais}

A aventura parece ser um corpo estranho à existência humana, mas, ao mesmo tempo e paradoxalmente, liga-se ao seu centro. A aventura funciona, de certa forma, como uma síntese de alguns de nossos sonhos e desejos. Neste sentido, Simmel (2000) contribui elucidando que a aventura é o coração pulsante de toda a sociedade.

A aventura mostra-se, neste quadro, como um importante desafio para refletirmos sobre a razão e os sentidos, as certezas e as incertezas do mundo contemporâneo, constituindo-se em formas sensíveis de vida social (MAFFESOLI, 2004). A construção social da aventura apresenta elementos centrais de nossa sociedade contemporânea, de suas formas de produção, segregação, diversão, etc. É despertada, nesta perspectiva, a possibilidade de melhor compreensão do outro, da natureza e, principalmente, de nós mesmos (MARINHO, 2008). Possibilidades estas observadas em determinados ritos e rituais aqui abordados.

As experiências de vida tornam-se ricas à medida que enfrentamos o desco- 
nhecido, quando saímos da mesmice. As viagens à natureza podem se constituir como uma das possibilidades para esse enfrentamento; um elemento que nos impulsiona para a busca do novo, das possibilidades, das transformações.

A errância, o deslocamento, seria a expressão de uma nova relação com o outro e com o mundo, apresentando características menos ofensivas, mais carinhosas, um tanto lúdicas, porém não menos trágicas. Características tendo como base a não permanência das coisas, dos seres e dos relacionamentos.

Obviamente esse quadro não está de acordo com as seguranças institucionais e instaura a agitação no estável ou a inquietação nas certezas, apontando a necessidade de uma postura de se trabalhar mais com ideias e inquietações que com propostas explicativas e certezas; mais com noções que definições; mais com flexibilidade que rigidez. Simbolismo e informalidade assumem um maior perfil na organização da existência humana.

O desafio contemporâneo requer a busca de reinvenções, de novos meios de convívio e valores diferenciados. Percebe-se uma busca contemporânea por algo indefinido, desconhecido, compondo instabilidades em um quadro instaurado na reciclagem dos desejos, bem como na reciclagem da própria vida (SEVCENKO, 1990).

Talvez essa busca pela natureza por meio de experimentações e novos comportamentos traduza um pouco de tudo isso, pois nela percebemos a influência de um mundo em crise, inquietante e instável, tomado por abalos brutais e mudanças rápidas: um universo social que se experimenta e do qual nossos corpos carregam os traços.

As discussões aqui empreendidas tiveram a pretensão de contribuir com novos desafios que se apresentam sobre os assuntos expostos, fortalecendo o repensar sobre importantes aspectos da vida atual, especialmente atrelados à natureza.

\section{Referências Bibliográficas}

BAUMAN, Z. Globalização: as consequências humanas. Rio de Janeiro: Jorge Zahar, 1999.

BAUMAN, Z. Identidade. Jorge Zahar, Rio de Janeiro, 2005.

BERNARDO, R. P.S.; MATOS, M. G. Desporto aventura e autoestima nos adolescentes, em meio escolar. Revista Portuguesa de Ciências do Desporto, v.3, n.1, p.3346, 2003.

BETRÁN, A. O.; BETRÁN, J. O. Análisis de la demanda potencial de las actividades físicas de aventura en la naturaleza en la ciudad de Barcelona. Apunts, Barcelona (España), n. 52, p.92-102, 1995.

BRASIL. Ministério do Meio Ambiente. Secretaria de Biodiversidade e Florestas. Diretoria de áreas protegidas. Diretrizes para visitação em Unidades de Conservação. Brasília (DF), 2006. 
BRUHNS, H. T. A busca pela natureza: Turismo e aventura. São Paulo: Manole, 2009.

BRYSON, B. Uma caminhada na floresta. São Paulo, Companhia das Letras, 1999.

CARNICELLI FILHO, S.; SCHWARTZ, G. M.; TAHARA, A. K. Fear and adventure tourism in Brazil. Tourism Management, Guildford, v.6, p. 953-956, 2010.

CICOUREL, A. Teoria e método em pesquisa de campo. In: GUIMARÂES, A. Z. Desvendando máscaras sociais. Francisco Alves, Rio de Janeiro,1975.

COSTA, V. L. M.; MARINHO, A.; PASSOS, K. C. M. Esportes de aventura e esportes radicais: propondo conceitos. Revista Motriz, Rio Claro, v.13, n.12, p.188, maio/ago. 2007.

DA MATTA, R. Carnavais, malandros e heróis. 4ª ed. Rio de Janeiro: Zahar, 1983.

DAMÁSIO, A. Em busca de Espinosa - prazer e dor na ciência dos sentimentos. São Paulo: Companhia das Letras, 2004.

FEATHERSTONE, M. O desmanche da cultura: globalização, pós-modernismo e identidade. Nobel/Sesc, 1997.

FIGUEIRA, M. L. M.; GOELLNER, S. V. Skate e mulheres no Brasil: fragmentos de um esporte em construção. Revista Brasileira de Ciências do Esporte, v.30, p.95110, 2009.

HUMBERSTONE, B. Inside/outside the Western "bubble": the nexus of adventure, adventure sports and perceptions of risk in UK and Mauritius. In: ORMROD, J.; WHEATON, B. (Eds). On the Edge: Leisure, consumption and the representation of adventure sports. Eastbourne: Leisure Studies Association, 2009.

LEITE, I. B. Antropologia da viagem: escravos e libertos em Minas Gerais no século XIX, Belo Horizonte, Ed. UFMG, 1996.

MAFFESOLI, M. Notas sobre a pós-modernidade: o lugar faz o elo. Tradução de Vera Ribeiro. Rio de Janeiro: Atlântica, 2004.

MAFFESOLI, M. Sobre o nomadismo: vagabundagens pós-modernas. São Paulo: Record, 2001.

MARINHO, A. As diferentes interfaces da aventura na natureza: reflexões sobre a sociabilidade na vida contemporânea. 2006. 154f. Tese (Doutorado em Educação Física) - Faculdade de Educação Física. Universidade Estadual de Campinas, Campinas (SP), 2006.

MARINHO, A. Lazer, aventura e risco: reflexões sobre atividades realizadas na natureza. Movimento, Porto Alegre, v.14, n.2, p.181-206, maio/ago, 2008.

MARINHO, A.; BRUHNS, H. T. (Orgs.). Viagens, Lazer e Esporte: o espaço da natureza. Barueri: Manole, 2006. 
MARINHO, A.; NASCIMENTO, J. V.; HUMBERSTONE, B. Leisure, tourism and adventure in Brazilian conservation units. In: LEISURE STUDIES ASSOCIATION LSA 2011 INTERNATIONAL CONFERENCE, Southampton, 2011. Anais... Southampton: Solent University, 2011. p.35.

NERY, P. R. A. A construção social da pessoa moderna e as práticas de deslocamento por prazer em uma abordagem comparada. Teoria e Sociedade. n.9, jun., 2002, p.63-77.

ORLANDI, E. P. As formas do silêncio, $5^{\mathrm{a}}$ ed., Campinas: Ed. Unicamp, 2002.

ORTIZ, R. Um outro território. São Paulo: Olho d'água, s/d.

PEREIRA, D. W.; ARMBRUST, I. Pedagogia da aventura: os esportes radicais, de aventura e de ação na escola. Jundiaí: Fontoura, 2010.

PIMENTEL, G. G. A. Qualidade de vida entre praticantes de esportes de aventura. Revista de Salud pública. v.10, n.4, p.561-570, 2008.

PIMENTEL, G. G. A.; SAITO, C. F. Caracterização da demanda potencial por atividades de aventura. Motriz, Rio Claro, v.16 n.1 p.152-161, jan./mar. 2010.

SANTOS, B. S. Pela mão de Alice: o social e o político na pós-modernidade. 9a .ed., São Paulo: Cortez, 2003.

SCHAFFER, R. M. O mundo dos sons. Correio da Unesco, n.4, p. 21-35, 1977.

SCHELLE, K. G. A arte de passear. São Paulo: Martins Fontes, 2001.

SEVCENKO, N. O enigma pós-moderno. In: OLIVEIRA, R. C. (Org.). Pósmodernidade, $3^{\mathfrak{a} e}$ ed., Unicamp, Campinas, 1990.

SIMMEL, G. La Aventura. In: Simmel, G. (Org.). Sobre la aventura. Barcelona, Ediciones Peninsula, 1988.

SIMMEL, G. The adventure. In: FRISBY, D.; FEATHERSTONE, M. (Ed.). Simmel on Culture. London: Sage, 2000. p.221-232.

TEIXEIRA, F. A.; MARINHO, A. Atividades de aventura: reflexões sobre a produção científica brasileira. Motriz, Rio Claro, v. 16, n. 3, p.536-548, jul./set. 2010.

\section{Notas}

'Ortiz (s/d, p.20) reserva o termo "mundialização" ao domínio específico da cultura e "globalização" à economia e tecnologia, embora considere a mundialização como expressão do processo de globalização das sociedades, enraizando-se em um tipo determinado de organização social, além de ser uma "concepção de mundo", um "universo simbólico". 
${ }^{2}$ Pesquisas realizadas para o CNPq ("Lazer e meio ambiente: a opção pelos esportes na natureza"- 1998 a 2000; "Esporte e natureza: a caminhada enquanto experiência sensível" - 2001 a 2003 e "Aprofundando elementos detectados nas atividades na natureza"- 2003-2006), cujos resultados estão condensados em Bruhns (2009). As discussões apresentadas também se fundamentam na pesquisa de doutorado de Marinho (2006).

${ }^{3} \mathrm{~A}$ identificação não se refere a uma atividade imitativa pela qual um sujeito modelase de acordo com outro, mas sim uma paixão assimiladora pela qual um ego inicialmente emerge (BUTLER, 2001).

Heloisa Turini Bruhns: Universidade Estadual de Campinas, Campinas, SP, Brasil. Email: luabola@uol.com.br

Link para o currículo Lattes: http://lattes.cnpq.br/6033060712348685

Alcyane Marinho: Universidade do Estado de Santa Catarina, Centro de Ciências do Desporto, Florianópolis, SC, Brasil.

Email: alcyane.marinho@hotmail.com

Link para o currículo Lattes: http://lattes.cnpq.br/7175741856017621

Data de submissão: 11 de dezembro de 2011

Data de recebimento de correções: 16 de janeiro de 2012

Data do aceite: 16 de janeiro de 2012

Avaliado anonimamente 